\title{
Early Adolescence
}

National Cancer Institute

\section{Source}

National Cancer Institute. Early Adolescence. NCI Thesaurus. Code C89331.

A human life stage that begins at twelve years of age and continues until eighteen

complete years of age. This phase marks the start of physical, physiological and

psychological changes that characterize pubertal growth and development. 